\section{Exploring Dimensions of Attitudes Toward Horticultural Activities}

\author{
Hui-Mei Chen ${ }^{1}$ and Hung-Ming Tu \\ Department of Horticulture, National Taiwan University, No. 1, Sec. 4, \\ Roosevelt Road, Taipei, 10617, Taiwan
}

\section{Chaang-Iuan Ho}

Department of Leisure Services Management, Chaoyang University of Technology, No. 168, Jifong East Road, Wufong Township Taichung County, 41349, Taiwan

Additional index words. gardening, leisure attitude, environmental benefit, escaping, leisure belief

\begin{abstract}
The main purpose of this research was to explore individuals' attitudes toward horticultural activities. The research was conducted in two stages. First, open-ended interviews were used to conceptualize attitudes toward horticultural activities, and seven themes and several subthemes of attitudes were induced. Based on the results, a questionnaire was then designed and a quantitative survey was conducted to identify the dimensions of attitudes toward horticultural activities and their interrelationships. Five dimensions of attitudes toward horticultural activities were extracted: increasing positive mood, improving the environment, leisure belief, improving social relationships, and escaping. These dimensions of attitudes toward horticultural activities had activitybased attributes that differed to some extent from those of general leisure. The dimension of improving the environment was particularly salient for horticultural activities. Propositions and recommendations to stimulate future research about developing a valid measurement instrument are offered.
\end{abstract}

Horticulture researchers typically focus on the science and technologies associated with crop production. Horticulture, which stems from the root words Hortus, meaning garden, and cultura, meaning culture, also plays an important role in human well-being. Kaplan (1973) provided empirical evidence that participating in gardening could bring people three types of psychological benefits: primary garden experiences (e.g., a desire to work in soil, wanting to see things grow), sustained interest (e.g., a valuable way to spend time, an opportunity to relax), and tangible benefits (e.g., enjoying the feeling of producing food, harvesting). Relf and Lohr (2003) reviewed a considerable amount of literature on human issues in horticulture and identified several benefits, including modifying the physical environment; developing the economy; enhancing communities and reducing public health hazards; healing individuals and improving their well-being; facilitating education; providing fruit, vegetables, and even medicinal substances; and generating jobs in plant production and recreation. Such findings suggest that horticultural activities offer people numerous personal benefits, and thus they are a worthwhile form of leisure.

To further promote horticultural activity as a form of leisure, it is crucial to first ascertain participants' attitudes about it. At-

Received for publication 19 Jan. 2010. Accepted for publication 16 May 2010.

${ }^{1}$ To whom reprint requests should be addressed; e-mail huimeichen@ntu.edu.tw. titudes represent a relatively positive or negative evaluation of a psychological object thus be used to predict behavior that affects leisure activities (Ragheb, 1980) and further influences their experience and satisfaction (Mannell and Kleiber, 1997; Ragheb and Tate, 1993). Relf et al. (1992) found that significantly more respondents who indicated they participated in gardening agreed with statements reflective of various values associated with nature, plants, and gardening. Yamane and Adachi (2008) found some positive relationships between attitudes toward gardening and health-related quality of life such as vitality and physical functioning.

To date, very few studies have explored participants' attitudes toward horticultural activities. In addition, previous researchers have limited their choice of measurements to some particular aspect of attitudes toward horticultural activities to the exclusion of others. Relf et al. (1992), for instance, used data from the U.S. National Gardening Survey to explore attitudes toward plants and gardening. In that survey, seven statements of attitudes toward plants and gardening were selected based on reported research on individuals' responses to plants and gardening. Most of these items, however, were related to psychological benefits such as feelings of relaxation, peace or tranquility, and enjoyment as well as a sense of control and wellbeing. One item measured the aspect of facilitating environmental beauty.

Unruh (2004) also focused on the psychological benefits of gardening, adopting a qual(Ajzen, 2005). Participants' attitudes can itative approach to explore the meaning of gardens for people with serious health problems. The research findings also mostly focused on psychological benefits, including enjoyment, emotional, sensual, restorative, spiritual, and cognitive. Another benefit included the economic aspect of worthwhile productivity. Participants in Unruh's study also identified gardening stresses such as insects, weather, limited economic resources, and time pressure. Yamane and Adachi (2008) explored the relationship between attitudes toward horticultural activities and quality of life using 10 items to measure horticultural activities. A review of these items indicates that half of the statements measured behaviors rather than attitudes. To summarize these previous studies, there is no valid and reliable measurement for attitudes toward horticultural activities.

According to Ajzen (2005), an attitude is a disposition to respond favorably or unfavorably to an object, person, institution, or event. Although formal definitions of attitude vary, most contemporary social psychologists seem to agree that the characteristic attribute of attitude is its evaluative (procon, pleasantunpleasant) nature (Ajzen, 2005). To some researchers, the definition of attitude consists of three components: cognitive, affective, and behavioral (Triandis, 1971). Ragheb and Beard (1982) adopted this three-component model for attitudes to develop the Leisure Attitude Scale (LAS), which has been widely adopted by other researchers in the leisure field. Applying the LAS, however, may be problematic for predicting participants' behaviors of horticultural activities. Drawn from basic psychological constructs, this scale comprises a three-component model for attitudes - cognitive, affective, and behavioral - which is centered on what the activity participants think about (cognitive aspect) and feel (affective aspect). A disadvantage of using the LAS as a measurement of attitudes toward horticultural activities is that participants may not identify other attributes of this activity such as environmental or economic advantages.

This review of previous research suggests that the full range of attitudes about horticultural activities still needs clarification. Instead of using modified versions of a ready-made scale, there is a need to explore sector-specific attributes of horticultural activities and develop a suitable system of measurement for attitudes toward horticultural activities. The main purpose of this research was to explore the dimensions and factor structure of participants' attitudes toward horticultural activities based on Ajzen (2005). This research provides a basis for future studies that could develop and verify a comprehensive measurement instrument of attitudes toward horticultural activities to fill existing research gaps between the areas of horticulture and leisure behavior.

To provide a sound conceptual foundation for investigating attitudes toward horticultural activities, the research consisted of two related studies. The first study used a qualitative approach with open-ended interviews to 
elicit and conceptualize participants' attitudes toward horticultural activities. Based on results from the first study, the second study adopted a quantitative method using questionnaires to identify the dimensions of attitudes toward horticultural activities and their interrelationships.

\section{Study 1: Conceptualizing Attitudes Toward Horticultural Activities}

\section{Method}

Open-ended interviews. In the first study, open-ended interviews, using convenience sampling, were executed on 8 and 9 Nov. 2008 at Chien-Guo Flower Market, the largest holiday retail flower market in Taipei (the capital of Taiwan). It is also a popular weekend spot for the citizens of the Taipei metropolis. Every weekend or holiday, the market attracts between 60,000 and 100,000 visitors (Taipei City Government, 2009).

Because an attitude is a favorable or unfavorable feeling with respect to a given object, to elicit participates' attitudes toward horticultural activities, the respondents were asked the following questions: "Do you like horticultural activities? Why?" "What do you think about horticultural activities?" "What else?"...

To gather the viewpoints of a broad crosssection of participants, a multiple-choice question was designed to ask respondents about the types of activities in which they participated in daily life. Key demographic data such as gender and age were also collected.

A total of 99 respondents were interviewed in this study. The determination of sample size was in accordance with Glaser and Strauss' (1967) concept of theoretical saturation. Saturation means that there were no additional data from additional interviews with new samples, and thus it could stop. The data were collected on one weekend ( 8 to 9 Nov.) at the holiday flower market. Then, one of the researchers started to analyze the interview data. After he coded and analyzed the data from respondents No. 1 through 50, an initial pool of 64 items was obtained. Then he analyzed the sample No. 51 to 70 , and six new items were coded. When he analyzed the sample No. 71 to 90 , only one item was found. Finally, when he analyzed the sample No. 90 to 99 , no more items were found. This meant that the information was saturated, and therefore the data collection was stopped. Eventually, a total of 71 items was obtained from replies of these 99 respondents.

Data analysis. The samples were evenly distributed across genders and a wide range of ages and included various types of horticultural activity participants. Of the 99 respondents, $51.5 \%$ were female and $48.5 \%$ were male. Only $10.1 \%$ of respondents were younger than age $30,13.1 \%$ were 31 to 40 years of age, $26.3 \%$ were 41 to 50 years of age, $37.8 \%$ were 51 to 60 years of age, and $13.1 \%$ were older than age 61. Approximately $90.1 \%$ of the sample selected indoor plants as their daily horticultural activity, and
$61.6 \%$ chose excursions (e.g., visiting botanical gardens, parks, farms, greenhouses, and attending flower exhibitions, etc.). Less than one-fourth of respondents selected arts and crafts $(23.2 \%$; e.g., flower arranging, artificial flowers, drying flowers, pressed flower craft, plant decoration, etc.) or outdoor plants $(20.2 \%)$ as their daily horticultural activity, respectively. A few respondents $(9.1 \%)$ declared that they participated in other plantrelated activities as well.

The data analysis of attitudes toward horticultural activities was based on a constant comparative analysis to construct emergent sets of themes from the interview transcripts. A thematic framework was developed as the interviews progressed, and this framework was revised in response to new information generated by additional interviews. The analysis was conducted in three steps. First, to ensure intercoder reliability, three researchers (the second author of the study and two independent researchers who were experienced in issues pertaining to horticulture and leisure) performed a separate, line-by-line, open-coding procedure, which was followed by mutual comparisons and negotiated outcomes. Initial descriptive coding using the participants' own words or phrases involved looking for repetition within and across the transcripts.

In the second step, after the open coding was completed for each transcript, three researchers worked independently to identify common concepts that illustrated the participants' descriptions. Similar code terms and phrases were grouped together and then regrouped to include all of the identified concepts into categories of similar topics. In the third step, the researchers went back and forth between the data and the classification system to identify dominant categories by recognizing code words or phrases that were repeated consistently within and across the transcripts. Findings represented a consensus regarding the analyses, and the interrater reliability was $87.5 \%$.

\section{Results}

The themes and subthemes derived from the interview data are presented in Table 1. Seven themes of attitudes toward horticultural activities were generated, including leisure belief, psychological benefit, physiological benefit, social benefit, educational benefit, aesthetic value, and ecological value. First, leisure belief refers to respondents' belief that horticultural activity is a type of leisure, entertainment, or hobby. Some respondents even valued horticultural activity as a positive activity. For example: "I think this is a good leisure activity" (No. 17) and "it requires little money, but the positive effect lasts very long" (No. 7). For some people, participating in horticultural activity was a way to spend time or structure their lives such as "planting makes me while away the time" (No. 50) and "I think horticultural activity is the most suitable for our retired people" (No. 50).
Regarding psychological benefit, the largest number of respondents stated that they could obtain many positive feelings (delight, pleasure, happiness, and comfort) to increase their positive mood by participating in horticultural activities, just like respondent No. 61 said: "Every morning, when I see the flower, it appears a happy day is beginning." Engagement in horticultural activity not only leads participants to relax and forget worries temporarily, but it also helps them transfer attention or even improve concentration. Respondent No. 23, for example, expressed, "Whenever devoting time to planting flowers, I can forget unhappy things or pressure in my life temporarily." In addition, some respondents asserted that horticultural activity had a spiritual function of mind cultivation such as: "it contributes to my spiritual well-being" (No. 49). Furthermore, some respondents could achieve self-fulfillment from horticultural activity to gain a sense of accomplishment (No. 9) or to facilitate self-growth (No. 57).

Compared with the number of respondents mentioning psychological benefits, very few identified physiological benefits. Some thought that horticultural activities were advantageous to improve physical health or to strengthen the body such as "It's beneficial for bodily health" (No. 86); a few others emphasized the effects of preventing diseases or curing the body such as "We won't get some diseases, such as heart disease" (No. 68). A possible explanation was that the respondents might have directly experienced psychological benefits but not health benefits. The health benefits might accumulate over many positive experiences of participating in horticultural activities, but an individual might find it difficult to attribute any such long-term health effects to only horticultural activities. The statements about health benefits may reflect beliefs about possible future benefits of horticultural activities, whereas statements about psychological benefits involve descriptions of experiences one has already had.

Referring to social benefits, participating in horticultural activities could provide chances for people to share with family and friends or to improve relationships with them. One respondent stated, for example, "I cultivate many plants such as bougainvillea; I usually multiply the plants and present them to friends" (No. 50). A few respondents further advocated that horticultural activities were helpful for social harmony. As one respondent stated: "I think everybody is nervous and feels stressful, no matter what his status is. I hope that this activity is promoted to release such pressure" (No. 33).

In term of educational benefits, horticultural activities could provide chances for participants to connect with and learn from nature, thus enriching their knowledge and sense of appreciation; for instance, "I can educate my kids to know about nature and to deal with the relationship between plants and the environment" (No. 33) and "I think it's great that we can develop the sense of aesthetics" (No. 55). 
Table 1. Themes and subthemes of attitudes toward horticultural activities from open-ended interviews.

\begin{tabular}{|c|c|c|c|}
\hline Theme & Subtheme & Contents & Percent \\
\hline \multirow[t]{7}{*}{ Leisure belief } & \multirow[t]{2}{*}{ Leisure activity } & A kind of leisure (or entertainment) & 24 \\
\hline & & A kind of hobby & 22 \\
\hline & \multirow[t]{3}{*}{ Positive activity } & A kind of positive activity & 15 \\
\hline & & $\begin{array}{l}\text { An inexpensive activity (with } \\
\text { substantial value) }\end{array}$ & 4 \\
\hline & & $\begin{array}{l}\text { A cheerful activity (or a interesting } \\
\text { activity) }\end{array}$ & 3 \\
\hline & \multirow[t]{2}{*}{ Spending time } & A way to spend time & 10 \\
\hline & & A way to arrange life & 5 \\
\hline \multirow{15}{*}{$\begin{array}{l}\text { Psychological } \\
\text { benefit }\end{array}$} & \multirow[t]{4}{*}{ Increasing positive mood } & Feeling pleased (or delighted, glad) & 62 \\
\hline & & Feeling comfortable & 18 \\
\hline & & $\begin{array}{l}\text { Gaining a sense of happiness } \\
\text { (or enjoyment) }\end{array}$ & 9 \\
\hline & & Feeling optimistic & 3 \\
\hline & \multirow[t]{3}{*}{ Relieving stress } & $\begin{array}{l}\text { Relaxing mood (or releasing stress, } \\
\text { reducing nervous tension) }\end{array}$ & 45 \\
\hline & & Feeling tranquil & 12 \\
\hline & & Forgetting worries & 12 \\
\hline & \multirow[t]{4}{*}{ Cultivating mind } & Fortifying self-possession & 31 \\
\hline & & Improving concentration & 4 \\
\hline & & Transferring attention & 3 \\
\hline & & Cultivating patience & 2 \\
\hline & \multirow[t]{4}{*}{ Achieving self-fulfillment } & Gaining a sense of accomplishment & 12 \\
\hline & & Obtaining self-growth & 10 \\
\hline & & Inspiring spirituality & 4 \\
\hline & & Gaining novel feelings & 4 \\
\hline \multirow{3}{*}{$\begin{array}{l}\text { Physiological } \\
\text { benefit }\end{array}$} & Improving health & Improving body health & 15 \\
\hline & Strengthening the body & $\begin{array}{l}\text { Strengthening body (or getting chance } \\
\text { of exercise) }\end{array}$ & 13 \\
\hline & Preventing diseases & Preventing diseases (or curing body) & 3 \\
\hline \multirow[t]{5}{*}{ Social benefit } & \multirow[t]{3}{*}{ Improving relationships } & $\begin{array}{l}\text { Improving family interaction (or } \\
\text { providing topics of conversation } \\
\text { with family) }\end{array}$ & 12 \\
\hline & & Providing a chance for sharing & 4 \\
\hline & & Improving relationships with friends & 3 \\
\hline & \multirow[t]{2}{*}{ Generating social harmony } & Generating social harmony & 3 \\
\hline & & Harnessing social pressure & 2 \\
\hline \multirow[t]{5}{*}{$\begin{array}{l}\text { Educational } \\
\text { benefit }\end{array}$} & \multirow[t]{2}{*}{ Enriching natural knowledge } & $\begin{array}{l}\text { Obtaining a chance to learn from nature } \\
\text { (or to have contact with nature) }\end{array}$ & 15 \\
\hline & & Enriching knowledge of plants (or nature) & 8 \\
\hline & \multirow[t]{3}{*}{ Cultivating disposition } & Cultivating a hobby & 8 \\
\hline & & Improving a zest for life & 5 \\
\hline & & Cultivating an aesthetic disposition & 4 \\
\hline \multirow[t]{5}{*}{ Aesthetic value } & \multirow[t]{2}{*}{ Beautifying the environment } & Beautifying environment & 21 \\
\hline & & Embellishing space & 10 \\
\hline & \multirow[t]{3}{*}{ Providing aesthetic experience } & Enriching visual experience & 14 \\
\hline & & Offering essential art & 10 \\
\hline & & Promoting living atmosphere & 6 \\
\hline \multirow{5}{*}{$\begin{array}{l}\text { Environmental } \\
\text { value }\end{array}$} & \multirow[t]{3}{*}{ Improving surroundings } & Purifying the air & 9 \\
\hline & & Improving surrounding quality & 5 \\
\hline & & Increasing green space & 4 \\
\hline & \multirow[t]{2}{*}{ Benefiting ecology } & Facilitating environmental protection & 6 \\
\hline & & Facilitating ecological preservation & 5 \\
\hline
\end{tabular}

Last but not least, respondents viewed horticultural activities as beneficial for the environment. Some respondents appreciated the aesthetic values of horticultural activities such as beautifying environment or providing aesthetic experience, for example: "Horticultural activity embellishes our living surroundings, and I think it's pretty good" (No. 17) and "Horticultural activity is a kind of art" (No. 86). Some people emphasized ecological values, including improving surroundings and benefiting ecology; for instance, "The air quality is not good in my workplace, so I use plants to decorate my place in order to reduce the harm" (No. 9) and benefit, could be reasonably grouped into the theme of aesthetic value as well. An additional empirical investigation was carried out in the follow-up study.

\section{Method}

Instrument. Based on the results of the first study, an initial pool of 71 scale items capturing attitudes toward horticultural activities was generated. All items were phrased positively and were scored on a 7-point scale $(1=$ strongly disagree to $7=$ strongly agree). This 71-item instrument was then pretested on 30 onsite purchasers at Chien-Guo Holiday Flower Market on 22 to 23 Jan. 2009. As a result of the pretest, 12 similar, blurred, and inappropriate items were deleted; and items were reduced to 59 questions that asked respondents about their attitudes toward horticultural activities. After careful examination, minor wording adjustments were made to clarify the statements and to respond to the collected comments. The revised pool of 59 items plus an additional seven items with respect to respondents' demographics and types of horticultural activities constituted the questionnaire for the follow-up survey.

Data collection. Data were collected from 27 Jan. 2009 to 28 Feb. 2009 at three major flower markets in three metropolises located in the northern, middle, and southern regions of Taiwan. With respect to sample size, DeVellis (2003) suggested that 300 is an adequate number of respondents to confirm the adequacy of items and to eliminate subject variance. In this study, a total of 401 valid questionnaires was collected in the three flower markets. The distribution of sample sizes among the three survey sites matched the distribution of the general populations in those metropolises. Using a systematic sampling approach, every fifth person passing through the entrance in flower markets was approached and asked to complete the survey.

The principal sociodemographic characteristics of the sample are shown in Table 2. The sample had more females $(61.3 \%)$ than males $(38.7 \%)$. The ages of the respondents had a concentrated distribution, in which the largest category (28.9\%) was 25 to 34 years of age. The next largest category $(24.9 \%)$ comprised respondents 35 to 44 years of age. Of the total sample, $59.9 \%$ of respondents were married. In regard to educational level, $40.6 \%$ of respondents were universityeducated, $16.0 \%$ had taken some college courses, and $18.5 \%$ had received postgraduate education. Nearly three-fourths of respondents $(72.6 \%)$ had a monthly income of less than 50,000 NT dollars $(\$ 1$ U.S. $=33$ NT dollars). The most common occupational category $(22.2 \%)$ was professional followed by blue collar workers $(18.2 \%)$, which included service workers, farm workers, machine operators, and so on.

Respondents were spread across five types of horticultural activities based on their multiple responses. Most respondents engaged in indoor plant activities $(73.8 \%)$ or excursions $(62.8 \%)$ with smaller portions participating in outdoor plant activities (17.5\%), arts and 
Table 2. Sociodemographic characteristics and activity participation of respondents $(\mathrm{N}=401)$.

\begin{tabular}{|c|c|c|}
\hline \multirow[b]{2}{*}{ Sociodemographics } & \multicolumn{2}{|c|}{ Total } \\
\hline & No. & $(\%)$ \\
\hline \multicolumn{3}{|l|}{ Gender } \\
\hline Male & 155 & $(38.7)$ \\
\hline Female & 246 & $(61.3)$ \\
\hline \multicolumn{3}{|l|}{ Age (years) } \\
\hline $15-24$ & 43 & $(10.7)$ \\
\hline $25-34$ & 116 & $(28.9)$ \\
\hline $35-44$ & 100 & $(24.9)$ \\
\hline $45-54$ & 81 & $(20.2)$ \\
\hline $55-64$ & 47 & $(11.7)$ \\
\hline 65 or older & 14 & (3.5) \\
\hline \multicolumn{3}{|l|}{ Marital status } \\
\hline Single & 161 & $(40.1)$ \\
\hline Married with no children & 23 & $(5.8)$ \\
\hline Married with children & 217 & $(54.1)$ \\
\hline \multicolumn{3}{|l|}{ Education level } \\
\hline Primary & 17 & $(4.2)$ \\
\hline High school & 83 & $(20.7)$ \\
\hline College & 64 & $(16.0)$ \\
\hline University & 163 & $(40.6)$ \\
\hline Postgraduate & 74 & $(18.5)$ \\
\hline \multicolumn{3}{|l|}{ Monthly income } \\
\hline Less than NT $\$ 25,000$ & 144 & $(35.9)$ \\
\hline NT $\$ 25,001-50,000$ & 147 & $(36.7)$ \\
\hline NT $\$ 50,001-75,000$ & 66 & $(16.5)$ \\
\hline NT \$75,001-100,000 & 22 & $(5.5)$ \\
\hline More than NT $\$ 100,001$ & 22 & (5.5) \\
\hline \multicolumn{3}{|l|}{ Occupation } \\
\hline Administrator & 22 & $(5.5)$ \\
\hline Professional & 89 & $(22.2)$ \\
\hline Technician & 32 & $(8.0)$ \\
\hline Clerk & 32 & $(8.0)$ \\
\hline Blue collar occupation ${ }^{2}$ & 73 & $(18.2)$ \\
\hline Retirement & 30 & (7.5) \\
\hline Housewife & 57 & $(14.2)$ \\
\hline Student & 48 & $(12.0)$ \\
\hline Other & 18 & $(4.5)$ \\
\hline \multicolumn{3}{|l|}{ Activity type ${ }^{y}$} \\
\hline Plants-indoor & 296 & $(73.8)$ \\
\hline Plants—outdoor & 70 & $(17.5)$ \\
\hline Arts and crafts activities & 44 & $(11.0)$ \\
\hline Excursions & 252 & $(62.8)$ \\
\hline Other plant-related activities & 31 & (7.7) \\
\hline
\end{tabular}

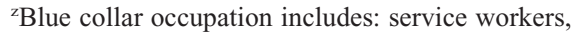
farm workers, machine operators, etc.

${ }^{y}$ Multiple choice.

crafts activities $(11.0 \%)$, or other-related activities $(7.7 \%)$.

\section{Results}

To explore the dimensions of attitudes toward horticultural activities, the survey data were analyzed in three steps. First, a factor analysis was used to identify the dimensionality of the 59 attitude items. The Kaiser-Meyer-Olkin (KMO) measure and Bartlett's test of sphericity were used to ensure that the data had inherent sufficient correlations to perform a factor analysis. The KMO index was 0.97 and Bartlett's test was significant at a level of 0.00 , which justified the use of this statistical technique. A principal component analysis with Varimax rotation was performed to generate the factors with eigenvalues greater than one. To reduce the number of items to a more manageable set, the criteria used to decide whether to delete an item were low factor loadings (below 0.5 ) or high factor loadings on more than one factor (Hair et al., 2006). The first factor analysis resulted in a seven-factor solution, which explained $64.33 \%$ of the variance. Based on these criteria, three items were deleted and the other 56 items remained.

Second, coefficient $\alpha$ obtained from the factor analysis was computed separately for each of the seven dimensions to ascertain the extent to which items making up each dimension shared a common core. The values of coefficient $\alpha$ ranged from 0.63 to 0.96 across the seven dimensions and suggested that deleting certain items from each factor would improve $\alpha$ values. The criteria used in deciding whether to delete an item were the low item's corrected item-to-total correlation, which indicated that the items had a relatively weak relationship with the other items, were also discarded. A set of 54 items with recomputed $\alpha$ values ranging from 0.75 to 0.96 was obtained.

Finally, this iterative sequence of analyses, which included re-examining the factor structure of the reduced item pool and recomputing the $\alpha$ value of each factor as well as deleting certain items with low item-to-total correlation, was repeated several times. After a series of computations, a final pool of 29 items representing five distinct dimensions with high $\alpha$ values ranging from 0.84 to 0.95 , which indicated good internal consistency among the items within each dimension, was extracted. The combined reliability was even higher (0.96). A summary of the attitude items of each factor and the $\alpha$ values, mean values, and corresponding factor loadings are summarized in Table 3 .

The process of measurement purification reduced the number of items from 59 to 29 . From these 29 items, the factor analysis extracted five factors, which explained $68.90 \%$ of the variance. As shown in Table 3, factor one was comprised of nine items with factor loadings greater than 0.62 . Of these nine items, six items measured mood (feeling glad, optimistic, pleased, comfortable, joyful, and happy), two items measured stress (feeling relaxed and tranquil), and one item measured health. As a result, this factor was labeled "increasing positive mood." In factor two, seven items had loadings exceeding 0.58 . It was labeled "improving the environment" because it included beautifying the environment (embellishing space), improving surroundings (improving living surroundings and air quality or increasing green space), benefiting ecology (facilitating ecological preservation and environmental protection), and one item that measured positive activity.

Factor three contained six items with loadings higher than 0.51 . Most of these six items were associated with the concept of leisure such as spending time (engaging in horticultural activity is a way to spend time), hobby cognition (engaging in horticultural activity is a kind of hobby or a way to cultivate hobbies), and positive activity iden- tification (horticultural activity is an activity with substantial value); therefore, factor three was labeled "leisure belief." Factor four comprised four items with loadings exceeding 0.65. All of these items measured improving relationship with family or friends, and consequently factor four was labeled "improving social relationships." Finally, there were three items with high loadings (greater than 0.71) in factor five. It was labeled "escaping" because these three items measured forgetting worries and transferring attention or represented a way to arrange life, which implied that engaging in horticultural activity provided a chance for people to escape from ordinary life.

\section{Discussion}

This research adopted both qualitative and quantitative methods to probe participants' attitudes toward horticultural activities. In the first study, seven themes and several subthemes of attitudes toward horticultural activities were induced from open-ended interviews with participants. According to these findings, a questionnaire was designed and distributed to further explore the factor structure of attitudes toward horticultural activities. Finally, five dimensions, comprising increasing positive mood, improving the environment, leisure belief, improving social relationships, and escaping, were identified.

It should be noted that according to the factor analysis, the dimension of "increasing positive mood" revealed the highest explanatory power, because it had the highest eigenvalue (14.37) of the five dimensions. This indicated that respondents highly emphasized psychological benefits as evidenced in such positive feelings such as being glad, pleased, optimistic, relaxed, tranquil, and comfortable as the essence of their attitudes toward horticultural activities. Participants also thought that engagement in horticultural activities could bring them enjoyment and happiness. This result highlighted the function of stress mitigation obtained from the experiences in the nature environment, as previous studies have indicated (e.g., Kaplan, 1993; Ulrich et al., 1991). Besides, it has been reported that plant cultivation promotes the $\alpha$ wave ratio and reduces negative feeling scores (Chang and Chen, 2005). These findings reveal that the positive psychological benefits are well supported.

The dimension of "escaping" was separated from the proposed theme of psychological benefits conceptualized in the first study. This study's finding revealed that engaging in horticultural activities can provide people opportunities to forget worries, transfer attention, or experience another way of life. This dimension of escaping emphasized the importance of the restorative benefits of contact with nature, as past studies have shown (Berto, 2005; Hartig et al., 2003; Kaplan, 1995). Researchers have argued that stresses of daily life can cause mental fatigue. Exposure to restorative environments provides people opportunities to escape from 
Table 3. Results of exploratory factor analysis by respondents' attitudes toward horticultural activities $(\mathrm{N}=401)$.

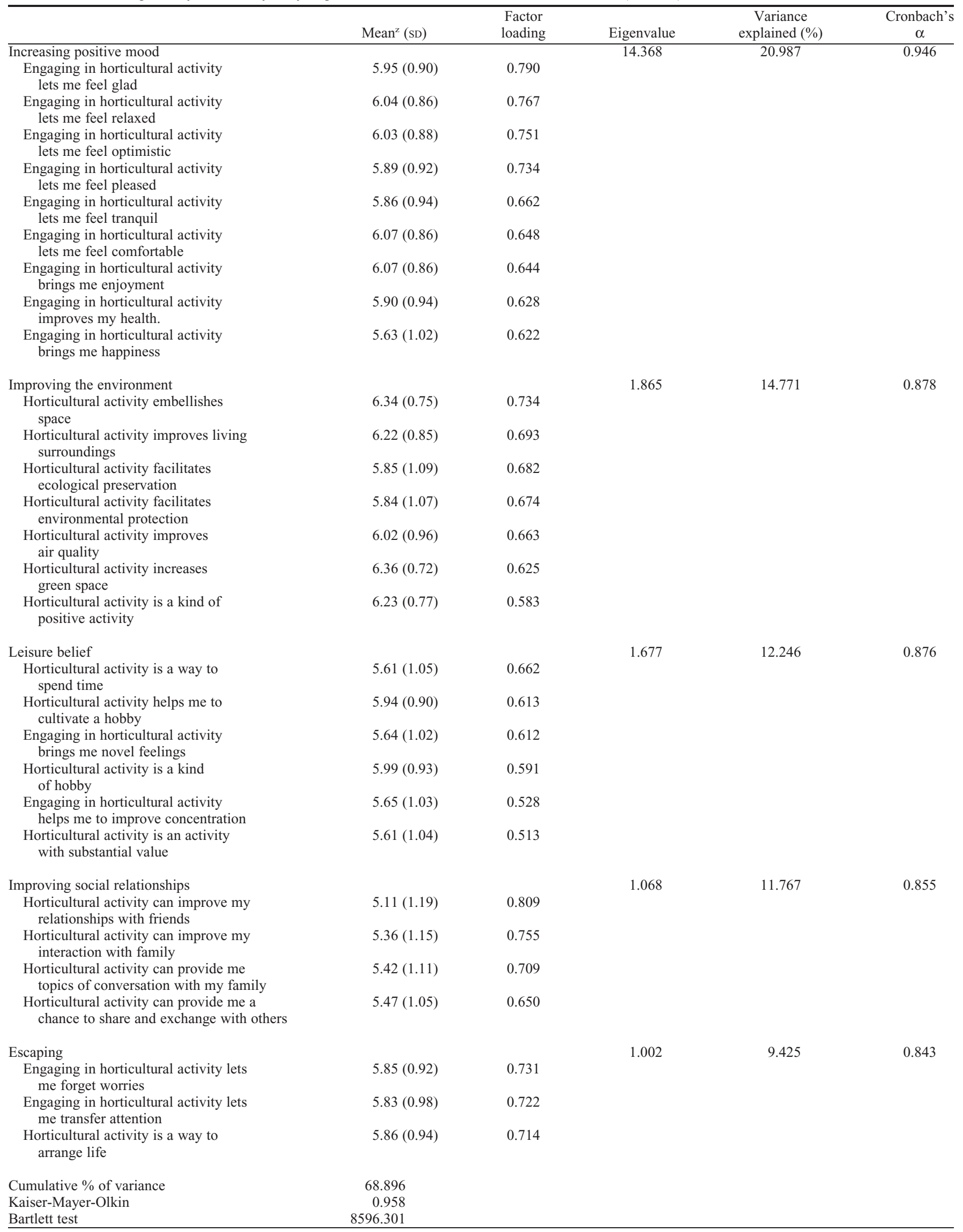

${ }^{\mathrm{z}} \mathrm{A}$ 7-point scale ( 1 = strongly disagree, 7 = strongly agree) was used. 
difficult aspects of life, which facilitates individuals' recovery from mental fatigue (Kaplan and Kaplan, 1989). Escape is also cited as a major reason for engaging in leisure activities in the field of leisure studies (Manfredo et al., 1996; Stokmans, 1999).

Consistent with past research indicating that social benefits are crucial to horticulture (Relf, 1973; Relf and Lohr, 2003), this study indicated that "improving social relationships" is an essential dimension of attitudes toward horticultural activities. Relf and Lohr (2003) reported on the social benefits of horticulture in their review article such as creating a positive community atmosphere. This viewpoint was anchored in the present study. "Improving social relationships" was emphasized as a distinct dimension of forming attitudes toward horticultural activities; however, it was difficult to ascertain this concept of social benefit in the LAS because this scale subsumed the benefits under the cognition component.

This research indicates that "improving the environment" was a critical dimension of participants' attitudes toward horticultural activities that comprised aesthetic value and ecological value. Horticulture literature has, at times, mentioned this environmental benefit of horticultural activities (Relf and Lohr, 2003). Most notably, "improving the environment" is a more specific attitude about horticultural activities than general leisure. While participating in other leisure activities, participants' attitudes toward such activities are usually referred to as personal benefits. In Stokmans's (1999) study, readers' reading attitudes were identified as enjoyment, escape, and development/use to the extent that these three aspects related to personal benefits. This research shows, however, that horticultural activities are beneficial not only for individuals, but also for the environment.

Besides, the dimension of "leisure belief" indicates that horticultural activity is indeed essentially a kind of leisure. Participants identified engaging in horticultural activities as a way to spend time or as a kind of hobby and an activity to cultivate hobbies. This finding provides significant evidence that horticultural activity is a worthwhile activity for both humans and the entire environment.

"Improving the environment" is a specific dimension of attitudes toward horticultural activities that is absent from the LAS. In addition to the dimension of "increasing positive mood," feelings of tranquility and comfort were the particular psychological benefits obtained from participating in horticultural activities in comparison with the items of the LAS, whereas feelings of pleasure and relaxation yielded from activity participation were identified in general leisure as well as horticultural activities. According to Driver et al. (1991), all kinds of leisure activities can generate psychological benefits. To some extent, these benefits may differ across activities. The proposed dimensions and scale items for attitudes toward horticultural activities in this research could be extended or modified as alternative paradigms for representing activity-based participation in the horticulture sector. A future study could make a strict comparison between adopting this new measurement and using the LAS to predict individuals' behaviors of participating in horticultural activities.

Several limitations of this study should be mentioned. The research results were drawn from the viewpoints of participants who engaged in horticultural activities as leisure rather than from farmers' perspectives. Farmers' attitudes toward horticultural activities may differ from those of leisure participants. In addition, focusing on only participants' opinions in this research may limit the interpretation of the findings. Future research could be conducted to seek nonparticipants' attitudes toward horticultural activities, including their possible negative attitudes toward horticultural activities.

\section{Literature Cited}

Ajzen, I. 2005. Attitudes, personality, and behavior. 2nd Ed. Open Univ. Press, New York, NY.

Berto, R. 2005. Exposure to restorative environments helps restore attentional capacity. J. Environ. Psychol. 25:249-259.

Chang, C. and P. Chen. 2005. Human response to window views and indoor plants in the workplace. HortScience 40:1354-1359.

DeVellis, R.F. 2003. Scale development: Theory and applications. 2nd Ed. Sage, Thousand Oaks, CA.

Driver, B.L., H.E.A. Tinsley, and M.J. Manfredo. 1991. The paragraphs about leisure and recreation experience preference scales: Results from two inventories designed to assess the breadth of the perceived psychological benefits of leisure, p. 263-286. In: Driver, B.L., P.J. Brown, and G.L. Peterson (eds.). Benefits of leisure. Venture, State College, PA.

Glaser, B.G. and A.L. Strauss. 1967. The discovery of grounded theory: Strategies for qualitative research. Aldine, Chicago, IL.
Hair J.F., Jr., R.E. Anderson, R.L. Tatham, and W.C. Black. 2006. Multivariate data analysis. 6th Ed. Prentice-Hall, Upper Saddle River, NJ.

Hartig, T., G.W. Evans, L.D. Jamner, D.S. Davis, and T. Garling. 2003. Tracking restoration in natural and urban field settings. J. Environ. Psychol. 23:109-123.

Kaplan, R. 1973. Some psychological benefits of gardening. Environ. Behav. 5:145-162.

Kaplan, R. 1993. The role of nature in the context of the workplace. Landsc. Urban Plan. 26: 193-201.

Kaplan, R. and S. Kaplan. 1989. The experience of nature: A psychological perspective. Cambridge Univ. Press, New York, NY.

Kaplan, S. 1995. The restorative benefits of nature: Toward an integrative framework. J. Environ. Psychol. 15:169-182.

Manfredo, M.J., B.L. Driver, and M.A. Tarrant. 1996. Measuring leisure motivation: A MetaAnalysis of the recreation experience preference scales. J. Leis. Res. 28:188-213.

Mannell, R.C. and D.A. Kleiber. 1997. A social psychology of leisure. Venture, State College, PA.

Ragheb, M.G. 1980. Interrelationships among leisure participation, leisure satisfaction and leisure attitudes. J. Leis. Res. 12:138-149.

Ragheb, M.G. and J.G. Beard. 1982. Measuring leisure attitude. J. Leis. Res. 14:155-167.

Ragheb, M.G. and R.L. Tate. 1993. A behavioural model of leisure participation, based on leisure attitude, motivation and satisfaction. Leis. Stud. 12:61-70.

Relf, P.D. 1973. Horticulture: A therapeutic tool. J. Rehabil. 39:27-29.

Relf, P.D. and V.I. Lohr. 2003. Human issues in horticulture. HortScience 38:984-993.

Relf, P.D., A.R. McDaniel, and B. Butterfield. 1992. Attitudes toward plants and gardening. HortTechnology 2:201-204.

Stokmans, M.J.W. 1999. Reading attitude and its effect on leisure time reading. Poetics 26:245261.

Taipei City Government. 2009. 2007 Chinese New Year activity schedule. Spring festival peony exhibition. 10 Aug. 2009. <http://english.taipei. gov.tw/>.

Triandis, H.C. 1971. Attitude and attitude change. Wiley, New York, NY.

Ulrich, R.S., R.F. Simons, B.D. Losito, E. Fiorito, M.A. Miles, and M. Zelson. 1991. Stress recovery during exposure to natural and urban environments. J. Environ. Psychol. 11:201230.

Unruh, A.M. 2004. The meaning of gardens and gardening in daily life: A comparison between gardeners with serious health problems and healthy participants. Acta Hort. 639:67-73.

Yamane, K. and M. Adachi. 2008. Roles of daily horticultural activities in physical and mental QOL for elderly adults. Acta Hort. 790: 165-171. 